\title{
Association of U.S. Dialysis Facility Neighborhood Characteristics with Facility-Level Kidney Transplantation
}

\author{
Laura Plantinga ${ }^{a, b}$ Stephen Pastan ${ }^{c, d}$ Michael Kramer ${ }^{a} \quad$ Ann McClellan ${ }^{a}$ \\ Jenna Krisher ${ }^{f}$ Rachel E. Patzer ${ }^{a, d, e}$ \\ ${ }^{a}$ Department of Epidemiology, Rollins School of Public Health, ${ }^{b}$ Laney Graduate School, Emory University, ' Division \\ of Renal Medicine, Department of Medicine, Emory University School of Medicine, ${ }^{d}$ Emory Transplant Center, Emory \\ Healthcare, e Division of Transplantation, Department of Surgery, Emory University School of Medicine, Atlanta, Ga., \\ fSoutheastern Kidney Council, ESRD Network 6, Raleigh, N.C., USA
}

\section{Key Words}

Neighborhood · Dialysis Facility · Kidney Transplantation ·

Socioeconomic Status

\section{Abstract}

Background: Improving access to optimal healthcare may depend on the attributes of neighborhoods where patients receive healthcare services. We investigated whether the characteristics of dialysis facility neighborhoods - where most patients with end-stage renal disease are treated were associated with facility-level kidney transplantation. Methods: We examined the association between census tract (neighborhood)-level sociodemographic factors and facility-level kidney transplantation rate in 3,983 U.S. dialysis facilities where kidney transplantation rates were high. Number of kidney transplants and total person-years contributed at the facility level in 2007-2010 were obtained from the Dialysis Facility Report and linked to the census tract data on sociodemographic characteristics from the American Community Survey 2006-2010 by dialysis facility location. We used multivariable Poisson models with generalized estimating equations to estimate the link between

\section{KARGER}

E-Mail karger@karger.com www.karger.com/ajn the neighborhood characteristics and transplant incidence. Results: Dialysis facilities in the United States were located in neighborhoods with substantially greater proportions of black and poor residents, relative to the national average. Most facility neighborhood characteristics were associated with transplant, with incidence rate ratios $(95 \% \mathrm{Cl})$ for standardized increments (in percentage) of neighborhood exposures of: living in poverty, $0.88(0.84-0.92)$, black race, 0.83 (0.78-0.89); high school graduates, 1.22 (1.17-1.26); and unemployed, 0.90 (0.85-0.95). Conclusion: Dialysis facility neighborhood characteristics may be modestly associated with facility rates of kidney transplantation. The success of dialysis facility interventions to improve access to kidney transplantation may partially depend on reducing neighborhood-level barriers.

(c) 2014 S. Karger AG, Base

\section{Introduction}

In the United States, geographic variations exist in access optimal healthcare, including access to kidney transplantation. Contextual and aggregated neighborhood-
C 2014 S. Karger AG, Basel

0250-8095/14/0402-0164\$39.50/0 
level factors influence access to healthcare and health outcomes, beyond the effects of individual-level risk factors. While area-based measures may miss much of the withinarea variation among individuals, there is also evidence that these measures capture information about other aspects of a place that is relevant to health outcomes [1]. For example, high neighborhood poverty is associated with a variety of poor outcomes, including the incidence of cardiovascular risk factors [2, 3], overweight/obesity [4], hypertension [5], and the incidence of end-stage renal disease (ESRD) [6].

Assessing area-based socioeconomic status has been particularly helpful in examining population-level health disparities [7]. Kidney transplantation is generally associated with decreased mortality and morbidity as well as better quality of life in ESRD patients [8-12], and disparities in access to kidney transplantation have been noted among pediatric $[13,14]$ and adult [15-17] ESRD patients among patients living in high-poverty neighborhoods compared to lower-poverty neighborhoods. Prior studies have also shown that dialysis facility-level factors, such as profit status [18], fewer number of fulland part-time staff within a facility [19], and a greater proportion of black patients within a facility [19], influence access to kidney transplantation in the United States.

The 2013-2016 ESRD Network Statement of Work from the Centers for Medicare \& Medicaid Services (CMS) requires networks to conduct pilot innovation projects [20], and 8 of 18 networks have chosen to conduct projects aimed at reducing racial disparity in transplant referral services [21]. Thus, intervention activities to increase access to kidney transplant referral programs are being planned for or are underway at hundreds of dialysis facilities across the nation. Linking the geospatial attributes of a neighborhood surrounding a dialysis facility - the location in which patients receive a majority of their ESRD care - with dialysis facility characteristics allows for assessment of the influence of neighborhood aggregate and contextual factors on facility-level access to kidney transplantation. This assessment could allow researchers, policymakers, and other stakeholders to identify facility neighborhood-level barriers to transplantation and create interventions that would effectively reduce these barriers and, potentially, reduce disparities in access to kidney transplantation. The purpose of this study was to determine whether characteristics of dialysis facility neighborhoods were associated with transplantation at the facility level, independent of relevant facility factors.

Dialysis Facility Neighborhood and

Transplantation

\section{Methods}

\section{Data Sources}

We obtained information on demographics, ESRD treatment factors, and outcomes at the levels of the facilities and CMS ESRD Networks (which regionally facilitate quality-of-care initiatives), by year and averaged over a 4-year period, from the 2007-2010 Dialysis Facility Report (DFR) data. Patients who were treated at transplant-only facilities or Veterans Affairs dialysis facilities or who received renal replacement therapy for $<90$ days are excluded from the DFR dataset [22]. These data were linked (geocoded) based on the dialysis facility location to the 2006-2010 American Community Survey (ACS), which provides data annually from randomly sampled subpopulations using U.S. Census Bureau-administered questionnaires on sociodemographic variables. These data, pooled over 5 years, were available at the level of the census tract, which we have used as a proxy for the dialysis facility neighborhood.

\section{Study Population}

The unit of analysis was the dialysis facility. We restricted our analysis to U.S. dialysis facilities ( $\mathrm{n}=3,983,76.0 \%$ of 5,244 geocoded and matched facilities) that reported a 4-year observed count of transplants, as well as 4-year average expected number of transplants and standardized transplant ratio (STR; observed number of transplants/expected number of transplants). The DFR does not report STR for facilities with fewer than 3 expected transplants over the 4-year period. Calculations of the expected number of transplants and STR excluded patients who were above 70 years old and those with transplants within the first 3 months of initiating dialysis. Dialysis facilities included in the analysis (vs. those excluded due to missing STR, $\mathrm{n}=1,261$ ) were located in neighborhoods with a higher percentage of residents who were black $(20.8$ vs. $10.3 \%$ ), unemployed (7.6 vs. $6.3 \%$ ), poor (18.3 vs. $14.3 \%$ ), or on public assistance ( 13.3 vs. $10.8 \%)$. The study group also included a lower percentage of residents who were married (46.1 vs. $52.0 \%$ ) or high school graduates ( 82.3 vs. $85.6 \%$ ).

\section{Outcome Variable}

Our primary outcome variable was facility-level, total number of observed first transplants in 4 years, divided by the total number of person-years contributed by the facility over this time period (i.e., facility-level incidence rate of transplants). While we also examined the facility-level STR and the observed number of transplants with expected number as offset as outcomes in sensitivity analyses, we used the observed number in primary analyses, due to the unknown statistical error generated in the calculation of STRs.

\section{Exposure Variables}

We hypothesized that a facility's neighborhood-level deprivation, disorder, and cohesion might influence facility-level transplantation rates $[23,24]$. Thus, we considered a variety of neighborhood characteristics as potential correlates of transplantation at the facility level, including demographics (indicators of cohesion and disorder), socioeconomic position (indicators of deprivation), and housing (indicators of deprivation and disorder). Demographic indicators included percentage of black population (\% black), percentage of the population who are married and are aged $15+(\%$ married), percentage of female-headed households (no 
husband present; \% female $\mathrm{HOH}$ ), and percentage of population with English as their primary language (\% English). Socioeconomic position indicators included percentage of population above 25 years old with high school graduation or equivalent studies (\% HS graduates), percentage of population above 15 years old in labor market but unemployed (\% unemployed), percentage of households with income less than the $100 \%$ federal poverty threshold (\% poverty), percentage of households with income less than 30,000 USD (\%USD <30K), Gini index of income inequality [25], and percentage of households receiving any public assistance (\% public assistance). Finally, housing indicators included percentage of house owners (\% owned), percentage of vacant houses (\% vacant), and percentage of overcrowded houses $(>1.5$ persons per room in the dwelling; \% crowded). All variables were standardized to the sample mean and standard deviation (SD) by using the formula [value $(X)$ - mean $(X)] / \operatorname{SD}(X)$, where $X=$ a facility neighborhood characteristic. Thus, all estimates can be interpreted as associations with standardized increments and can be compared directly across indicators, regardless of the sample distributions.

\section{Other Variables}

Dialysis facility and ESRD Network characteristics (from the DFR data), which we previously found to be associated with facility-level transplantation [19], were examined as potential correlates of the association between facility neighborhood characteristics and STR, including, at the facility level (4-year averages): percentage of patients who were black, percentage of patients who had no insurance prior to start of ESRD, percentage of patients with diabetes, number of staff at the facility, mean age, mean dialysis vintage, percentage of people treated with peritoneal dialysis, percentage of people with an arteriovenous fistula, percentage of people using erythropoietin-stimulating agents, percentage of people employed and profit status. At the network level, we examined the transplant center density as a potential correlate, as well as the Network itself and the local U.S. organ allocation [Organ Procurement Organization (OPO)] region.

\section{Data Analysis}

We described the facility neighborhood characteristics (means and SDs) and compared them with those of all U.S. neighborhoods. We adjusted for those factors that remained correlates of the association between neighborhood characteristics and facility transplantation rates, in the presence of facility, Network, and other neighborhood characteristics, after backward elimination, with variables resulting in a $<10 \%$ change in estimate being dropped sequentially. We used marginal negative binomial models and generalized estimating equations to account for the clustering of facilities within a network, with observed count as the outcome and person-years as the offset. Thus, the reported estimates represent an incidence rate ratio (IRR) associated with each single-unit (= $1 \mathrm{SD}$ ) change in the neighborhood indicator. Multilevel models with clustering at the neighborhood level were not necessary because a majority of neighborhoods included in this analysis (88\%) had only a single facility. Results accounting for the small level of clustering at the neighborhood level were not substantially different from those presented here (data not shown), and robust estimates of variance were used in all multivariable models [26]. These models were compared and sequential adjustment was performed for various correlates identified in the backward elimination process described earlier. Using the Atlanta, Georgia, metropolitan statistical area as an illustrative example, we also mapped facility locations with their associated STR based on selected neighborhood characteristics. This geographic level allows for the examination of facility STR distribution along with census tract characteristics in finer detail than national or state-level maps, despite the limitation that it may not reflect nationwide patterns. We examined the robustness of our modeling assumptions in sensitivity analyses with multiple parameterizations of the outcome (online suppl. material; for all online suppl. material, see www.karger. com/doi/10.1159/000365596). SAS v. 9.3 (SAS Institute, Cary, N.C., USA) and Stata v. 13 (StataCorp, College Station, Tex., USA) were used for all analyses. Geocoding and spatial joining were performed using ArcGIS v. 10.1 (ESRI, Redlands, Calif., USA).

\section{Results}

\section{Dialysis Facility Neighborhood Characteristics}

A total of 3,983 dialysis facilities in 3,706 neighborhoods were included in this study population, representing 235,275 U.S. ESRD patients aged less than 70 in 2010. The geographic distribution of these dialysis facilities (fig. 1) suggests that a majority of dialysis facilities, as expected, are located in the South, Northeast, and West Coast and in urban areas. Table 1 shows the average characteristics of the neighborhoods in which these dialysis facilities were located, with a comparison to the average characteristics of all U.S. neighborhoods; here neighborhood is defined by census tract. Overall, the neighborhoods that contain dialysis facilities have a substantially greater proportion of black, unmarried, and poor residents and residents who do not own homes, relative to the national average. However, income inequality, lack of education, and unemployment in dialysis facility neighborhoods were not substantially different from overall U.S. average.

\section{Association of Dialysis Facility Neighborhood \\ Characteristics with Kidney Transplantation}

The facility-level IRRs and 95\% confidence intervals from marginal negative binomial models with observed count as the outcome and person-years as the offset (with GEE to account for correlation between facilities within tracts and within networks) are shown in table 2. Effects of the facility neighborhood factors were generally modest and were attenuated with adjustment for facility and census tract characteristics. After adjustment for facility and neighborhood characteristics and ESRD Network, each standardized increase in percentage of high school graduates $(\sim 12 \%$; see table 1$)$ in dialysis facility neighborhoods was associated with 15\% higher facility-level incidence of kidney transplant. Conversely, after full adjust- 


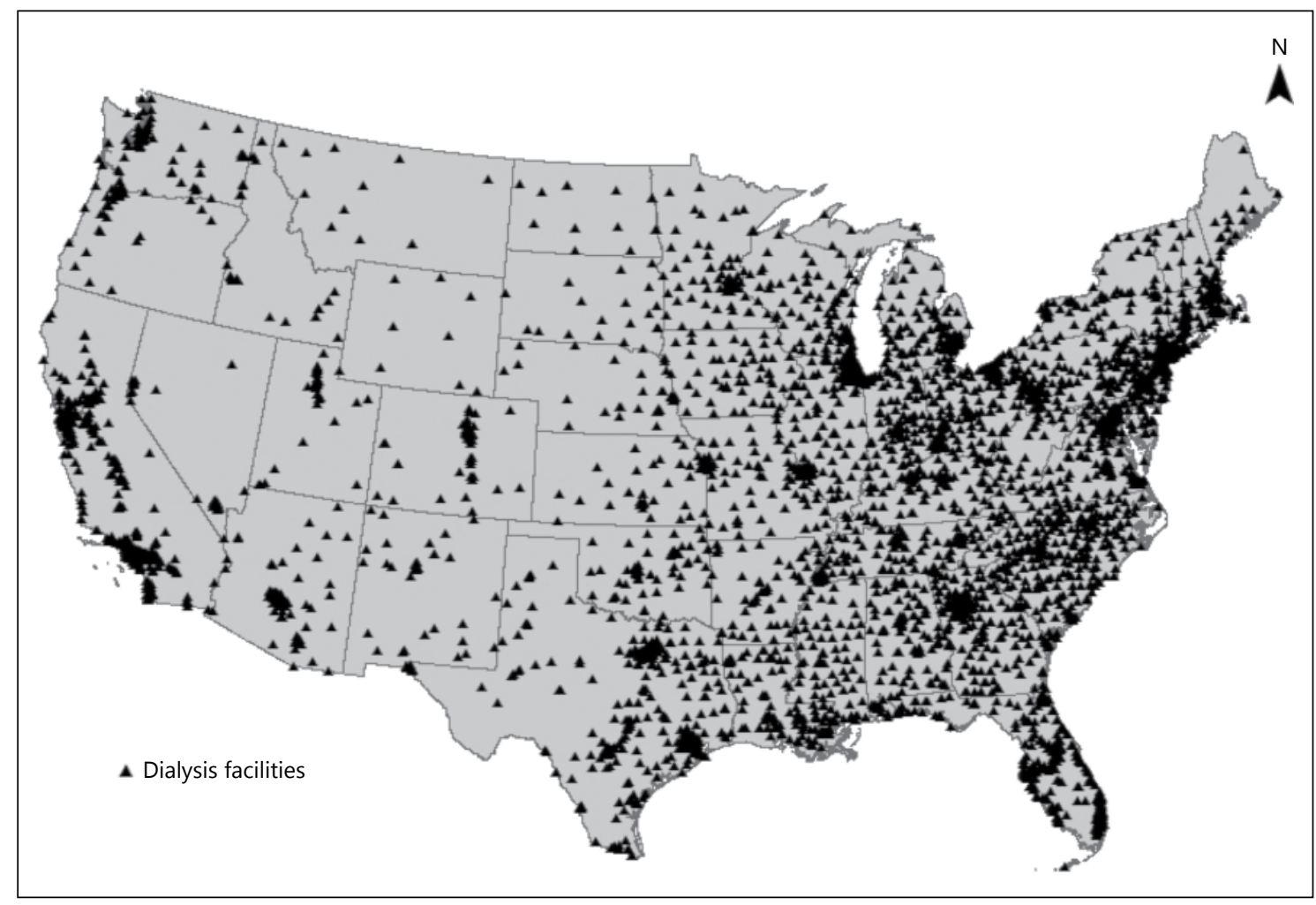

Fig. 1. Geographic distribution of U.S. dialysis facilities reporting standardized kidney transplant ratios in 20072010.

ment, each standardized increase in percentage of black residents, married residents, unemployed residents, and households living in poverty in dialysis facility neighborhoods was associated with 2, 7, 3, and 9\% lower facilitylevel incidence of kidney transplant, respectively (table 2), although not all the associations were statistically significant. Adjustment for the patient:staff ratio rather than number of staff and additional adjustment for size of dialysis organization/chain did not affect results (data not shown). Additional adjustment for ESRD Network and OPO region did not result in substantially different estimates or levels of statistical significance (data not shown). ESRD Network- and OPO region-specific associations between neighborhood characteristics and facility transplantation rates generally did not differ from each other $\left(P_{\text {interaction }}>0.05\right)$ or from the national estimates (table 2). Sensitivity analyses suggested that parameterization of the outcome did not substantially affect the results (online suppl. material).

Facility locations, with their associated STR, are shown by selected neighborhood characteristics in the Atlanta, Georgia, metropolitan statistical area (fig. 2). In this area, facilities with low STRs (i.e., facilities where fewer transplants than expected happened) were more frequently located in neighborhoods with a greater percentage of black residents (fig. 2A), with a greater percentage of household poverty (fig. 2B), and with a lower percentage of high school graduates (fig. 2C), whereas the opposite was seen for facilities with high STRs (i.e., more transplants than expected). However, there is some overlap, and facilities with STRs in the expected middle range were scattered throughout facility neighborhoods of varying socioeconomic status.

\section{Discussion}

In this analysis of more than 3,000 dialysis facilities representing over 200,000 ESRD patients, we found that dialysis facility neighborhood attributes of a higher proportion of residents reporting black race, lower educational attainment, and greater levels of poverty were associated with lower facility-level transplant rates. These modest associations were further attenuated in models 
Table 1. Characteristics of census tracts with U.S. dialysis facilities (2007-2010) reporting standardized transplant ratios and expected number of transplants $(\mathrm{n}=3,706)$ and all U.S. census tracts $(\mathrm{n}=72,378)$

\begin{tabular}{|c|c|c|c|c|}
\hline Indicator & \multicolumn{2}{|c|}{ U.S. census tracts with dialysis facilities } & \multicolumn{2}{|c|}{ All U.S. census tracts } \\
\hline \% black & $20.4 \pm 25.6$ & $2.0-30.0$ & $13.6 \pm 22.6$ & $0.6-14.6$ \\
\hline$\%$ married & $46.4 \pm 12.6$ & $38.7-55.3$ & $51.7 \pm 13.5$ & $43.6-61.4$ \\
\hline$\%$ female $\mathrm{HOH}$ & $25.2 \pm 14.4$ & $14.7-32.2$ & $20.4 \pm 14.1$ & $10.6-26.4$ \\
\hline$\%$ HS graduates & $82.4 \pm 11.7$ & $76.0-91.4$ & $84.3 \pm 12.1$ & $78.5-93.2$ \\
\hline$\%$ unemployed & $7.6 \pm 5.2$ & $4.0-9.9$ & $7.0 \pm 5.2$ & $3.6-8.9$ \\
\hline$\%$ poverty & $18.0 \pm 12.6$ & $8.2-24.9$ & $14.8 \pm 12.3$ & $5.9-20.1$ \\
\hline$\%<\mathrm{USD} 30 \mathrm{~K}$ & $29.0 \pm 14.7$ & $17.5-38.6$ & $24.5 \pm 14.4$ & $13.5-32.8$ \\
\hline Gini index & $0.43 \pm 0.07$ & $0.38-0.46$ & $0.41 \pm 0.07$ & $0.37-0.45$ \\
\hline$\%$ public assistance & $13.1 \pm 10.6$ & $4.9-18.6$ & $10.9 \pm 10.4$ & $3.4-15.0$ \\
\hline
\end{tabular}

$\mathrm{P}$ values for comparison are not shown due to overlap of census tracts and large sample size effects. IQR, interquartile range; $\%$ black, percentage of population reporting black race; \% married, percentage of the population aged $15+$ reporting being married; \% female $\mathrm{HOH}$, percentage of households reporting female head of household; \% English, percentage of population reporting English as their primary language; \% HS graduates, percentage of population $25+$ reporting being high school graduates or equivalent; \% unemployed, percentage of population $15+$ reporting be- ing in labor market but unemployed; \% poverty, percentage of households reporting income $<100 \%$ federal poverty threshold; $\%<$ USD $30 \mathrm{~K}$, percentage of households reporting income $<$ USD 30,000; Gini index, Gini index of income inequality; \% public assistance, percentage of households reporting receipt of any public assistance; \% owned, percentage of housing that is owned; \% vacant, percentage of housing that is vacant; \% crowded, percentage of housing that is crowded ( $>1.5$ persons per room in the dwelling). that adjusted for important dialysis facility level factors that influence transplant access. Consistent with prior studies showing that neighborhood poverty is a risk factor for delayed access to healthcare and, specifically, kidney transplantation $[15,27]$, our results also suggested that the socioeconomic characteristics of the neighborhood in which patients receive much of their dialysis care may have some influence on access to kidney transplantation at the dialysis facility level. However, the study also confirmed that these potential effects do not appear to differ substantially or systematically between the various regions in the United States. Further, our results suggested that these associations may not be fully explained by the attributes of the facility that are strongly associated with facility-level standardized transplantation ratios in the United States [19]. Thus, identifying dialysis facilities located in neighborhoods that have a high proportion of blacks, lower education levels, and high poverty - all markers for low transplant access - could help focus on intervention efforts to break facility neighborhood barriers and improve access to kidney transplantation within dialysis facilities.

However, as noted, the observed associations are generally modest. There are several potential explanations for the observed modest impact of neighborhood attributes of a dialysis facility on facility-level transplantation rates. It is possible that the neighborhoods in which patients receive ESRD care at the dialysis facility differ from those in which they spend much of their time outside the facility. It is also possible that the influences of residential, leisure, and workplace neighborhoods on access to care are stronger than those of the facility neighborhoods. $\mathrm{Cu}-$ mulative lifetime effects of neighborhood characteristics, which could not be recorded here, could also influence access to and seeking of medical care. Residential neighborhood or cumulative neighborhood effects might be more relevant than dialysis facility neighborhood effects to kidney transplantation access because there is possibly 
Table 2. Facility-level incidence rate ratios for kidney transplantation associated with standardized increments in dialysis facility tract characteristics, U.S. dialysis facilities 2007-2010

\begin{tabular}{|c|c|c|c|}
\hline \multirow[t]{2}{*}{ Tract Characteristic } & \multicolumn{3}{|c|}{ Incidence rate ratio for transplantation per $\mathrm{SD}^{*}(95 \% \mathrm{CI})$} \\
\hline & Crude** & $\begin{array}{l}\text { Adjusted for facility } \\
\text { characteristics }\end{array}$ & $\begin{array}{l}\text { Adjusted for facility and } \\
\text { tract characteristics }\end{array}$ \\
\hline$\%$ black & $0.83(0.78-0.89)$ & $0.94(0.92-0.97)$ & $0.98(0.95-1.01)$ \\
\hline$\%$ married & $1.03(0.99-1.08)$ & $1.02(1.00-1.05)$ & $0.93(0.89-0.96)$ \\
\hline$\%$ female $\mathrm{HOH}$ & $0.86(0.82-0.91)$ & $0.92(0.89-0.95)$ & $0.97(0.91-1.02)$ \\
\hline \% English & $1.11(0.94-1.09)$ & $1.04(0.99-1.09)$ & $1.02(0.97-1.07)$ \\
\hline$\%$ HS graduates & $1.22(1.17-1.26)$ & $1.17(1.14-1.19)$ & $1.15(1.10-1.20)$ \\
\hline$\%$ unemployed & $0.90(0.85-0.95)$ & $0.93(0.90-0.96)$ & $0.97(0.93-1.01)$ \\
\hline$\%$ poverty & $0.88(0.84-0.92)$ & $0.90(0.88-0.93)$ & $0.91(0.88-0.93)$ \\
\hline$\%<\mathrm{USD} 30 \mathrm{~K}$ & $0.87(0.83-0.91)$ & $0.90(0.87-0.93)$ & $0.93(0.88-0.99)$ \\
\hline Gini index & $0.99(0.95-1.11)$ & $0.98(0.95-1.01)$ & $1.02(0.99-1.05)$ \\
\hline$\%$ public assistance & $0.84(0.80-0.87)$ & $0.89(0.86-0.92)$ & $0.91(0.86-0.95)$ \\
\hline$\%$ owned & $0.99(0.95-1.04)$ & $1.02(0.99-1.05)$ & $0.95(0.91-0.99)$ \\
\hline$\%$ vacant & $0.90(0.86-0.95)$ & $0.93(0.90-0.97)$ & $0.96(0.93-0.99)$ \\
\hline$\%$ crowded & $0.95(0.91-0.98)$ & $0.93(0.91-0.98)$ & $0.95(0.92-0.98)$ \\
\hline
\end{tabular}

Incidence rate ratios can be interpreted as the change in transplant incidence associated with each standardized increase in tract characteristic; e.g., each standardized increase in percentage of high school graduates in dialysis facility neighborhoods was associated with $15 \%$ higher facility-level incidence of kidney transplant, after adjustment for facility- and tract-level characteristics. $\%$ black, percentage of population reporting black race; \% married, percentage of the population aged $15+$ reporting being married; $\%$ female $\mathrm{HOH}$, percentage of households reporting female head of household; \% English, percentage of population reporting English as their primary language; $\%$ HS graduates, percentage of population 25+ reporting being high school graduates or equivalent; \% unemployed, percentage of population $15+$ reporting being in labor market but unemployed; \% poverty, percentage of households reporting income $<100 \%$ federal poverty threshold; $\%<$ USD $30 \mathrm{~K}$, percentage of households reporting income <USD 30,000; Gini index, Gini index of income inequality; \% public assistance, percentage of households reporting receipt of any public assistance; $\%$ owned, percentage of housing that is owned; \% vacant, percentage of housing that is vacant; $\%$ crowded, percentage of housing that is crowded ( $>1.5$ persons per room in the dwelling). Adjustment: facility-level characteristics included percentage of patients reporting mean age, black race, percentage with no insurance at the start of dialysis, percentage with diabetes, and number of facility staff; tract-level characteristics included percentage of population that was black and percentage of households living below the poverty threshold.

* SD, sample standard deviation in exposure of interest. ** Association between selected neighborhood characteristic and outcome (no covariates). a time lag between some of these exposures and their potential effects [28].

Further, access to kidney transplantation is likely to depend on a combination of influences of care received before the onset of ESRD and care received at the dialysis facility during treatment for ESRD. We know that receiving pre-ESRD care from nephrologists is associated with increased likelihood of transplantation [29], and preESRD care is likely to occur in neighborhoods that differ from those that have dialysis facilities. If pre-ESRD care is not related to dialysis facility neighborhood characteristics, which is suggested by the results of a previous study in which we showed a null effect of neighborhood poverty on receipt of pre-ESRD care [30], this may partially explain the modest impact of facility neighborhood characteristics on transplantation.

Dialysis Facility Neighborhood and Transplantation
Additionally, our results suggest that U.S. dialysis facilities tend to be located in neighborhoods with worse values for socioeconomic indicators than the average U.S. neighborhood. Establishment of dialysis facilities in neighborhoods that vary less in terms of socioeconomic indicators when compared to the entire population of U.S. neighborhoods could mask effects of the facility neighborhood. The inclusion of patients from varying neighborhoods and backgrounds may also mask effects, if travel time is relatively unimportant to some dialysis patients in their facility preferences [31]; such patients differ from those unwilling to travel in terms of resources.

Another important reason that the observed effect of dialysis facility characteristics on facility-level transplantation rates may be modest is the inappropriate adjust- 
Fig. 2. Distribution of dialysis facility standardized kidney transplant ratios (20072010) by census tract-level race (A), poverty (B), and education (C) in the Atlanta, Georgia, metropolitan statistical area. STR = standardized transplant ratio; FPL = federal poverty line. Symbols at dialysis facility locations represent the level of STR: low $(<0.8$, open circles), middle (0.8-1.2, asterisks), and high ( $>1.2$, filled squares).
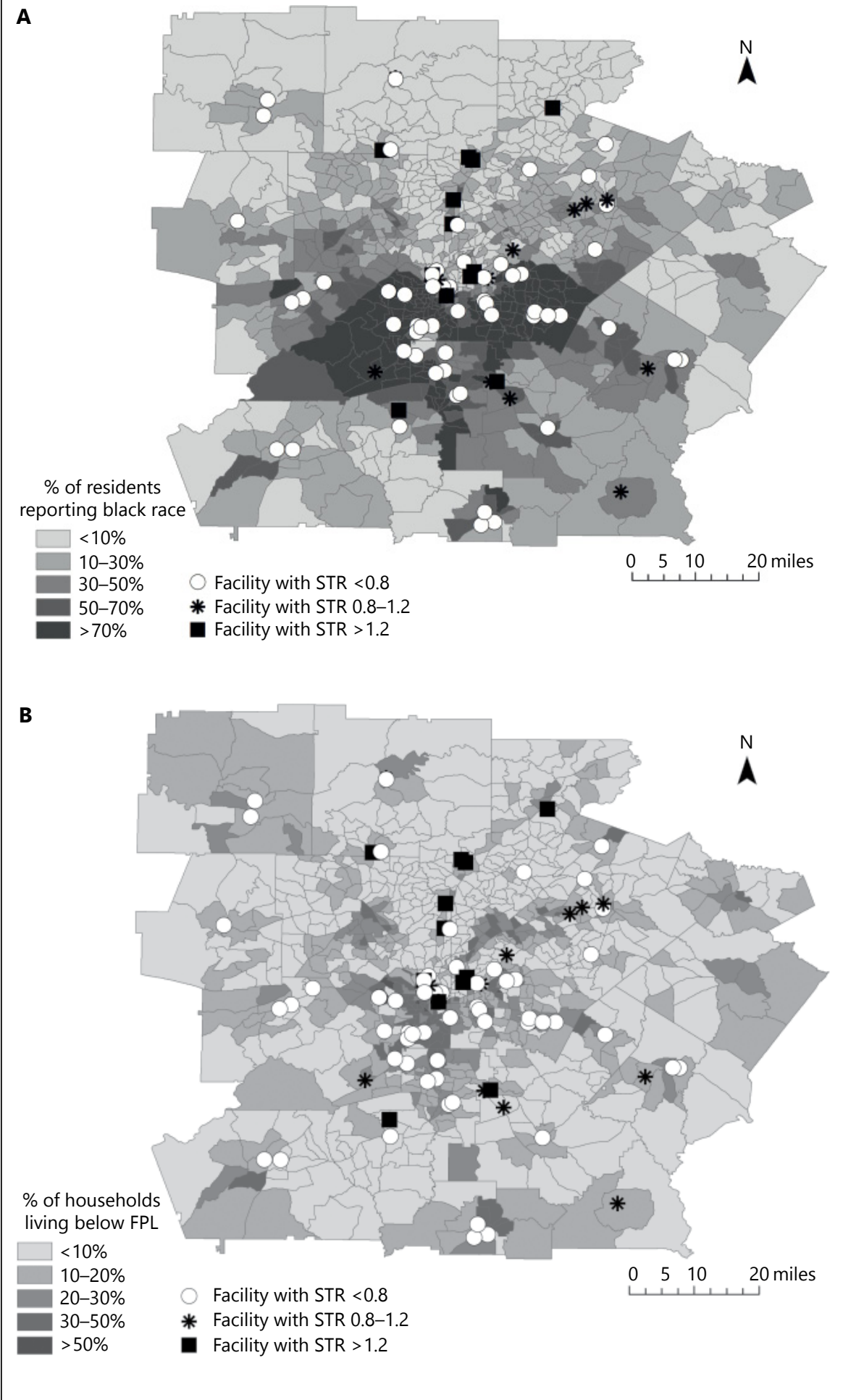

(For figure $2 c$ see next page.) 


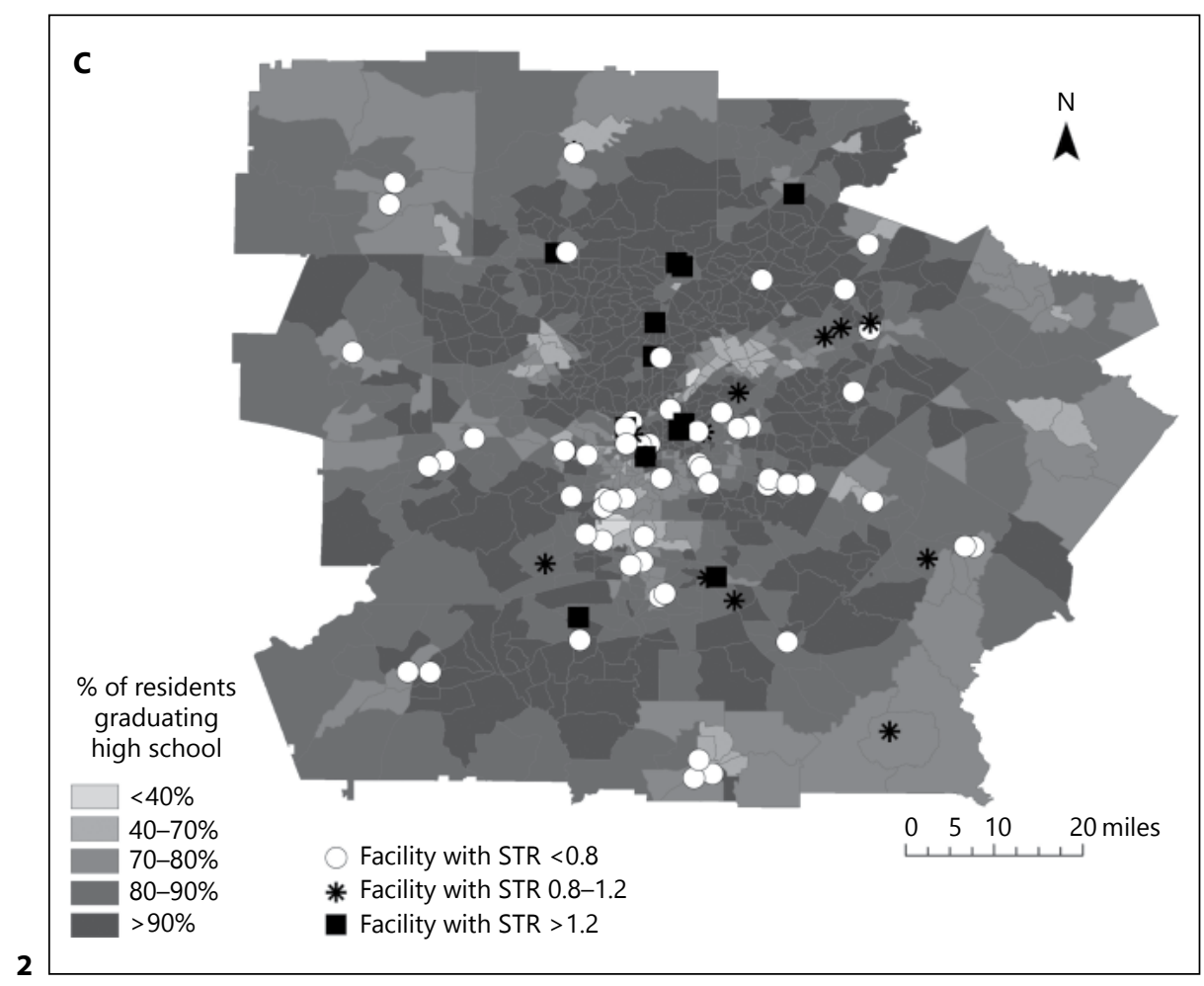

ment made for covariates. While adjustment for confounders is necessary to estimate the independent effect of each facility neighborhood characteristic on transplantation at the facility level, it is not always clear whether variables are confounders or intermediates [28]. For example, we found that, without adjustment, a standardized increase in percentage of the black race in a dialysis facility neighborhood was associated with $17 \%$ lower facility transplantation rates (effect $=-17 \%$ ). With adjustment for facility factors, this effect dropped to only $-6 \%$, and with further adjustment for neighborhood poverty, the effect was only $-2 \%$. While this attenuation of effect might well indicate that the unadjusted estimate was confounded by these factors, it might also indicate that the effect of neighborhood black race was mediated by at least some of these factors - e.g., it seems entirely plausible that facility-level black race and/or neighborhood-level poverty might be influenced by neighborhood black race and that these factors, in turn, would influence access to transplantation. Thus, our fully adjusted results may represent estimates of direct effects of neighborhood characteristics rather than merely independent, total effects. And in studies of neighborhood characteristics, the direct effect may be of less importance than the total effect, particularly in the planning of targeted public health interven- tions [28]. If we considered only the crude, or total neighborhood effect on facility-level transplant access, nearly all of the neighborhood characteristics we examined (black, female-headed households, high school graduates, unemployed, living in poverty, income $\mathrm{USD}<30,000$, public assistance recipients, and vacant and crowded housing) are important (albeit modest in some cases) influences on transplant access. Further, examining only total effects, neighborhood marital status had a null-topositive influence on facility transplant rates, rather than an incongruously negative influence, as seen in the adjusted analyses.

In addition to the limitations discussed earlier, this is an ecologic study, and thus inferences about individual patients cannot be made on the basis of these results. The association between individual-level poverty and transplant access is well established, and it is possible that individual factors, if available, might explain the modest associations observed here. However, as mentioned earlier, it can also be argued that whether adjustment for these individual factors is appropriate depends on whether the factors act as confounders of the association between neighborhood-level factors and facility-level transplantation, intermediates in the pathway between this exposure and outcome, or both [28]. Further, individual factors 
may be of less importance when planning interventions to increase transplantation access at the facility level. Second, there is a possibility for selection bias due to the exclusion of the missing STR. About $24 \%$ of facilities were excluded due to missing STR, and these excluded facilities generally were located in neighborhoods with better socioeconomic status, per the indicators examined here. Third, there is the potential for residual confounding by unknown or unmeasured factors at multiple levels. For example, the percentage of a tract dedicated to residential vs. non-residential zoning and location of hospitals and/ or transplant centers within the same or nearby tracts may influence other facility neighborhood characteristics as well as facility transplant rates. Finally, because multiple indicators of socioeconomic status were examined, some statistically significant findings could be due to chance alone.

Despite these limitations, these national data support that neighborhood factors are important drivers of the likelihood of transplantation at the facility level. With adjustment for potentially mediating facility characteristics, these factors still have important, but more modest, effects. While these results should be considered hypothesis-generating, it may be important to consider that the success of interventions to increase access to kidney transplantation may depend, in part, on these neighborhood effects, which are not necessarily modifiable by providers. If U.S. facilities are to be compared on the basis of their transplant rates, adjustment for the neighborhood effect may be essential to make such comparisons fair and justified. In fact, the National Quality Forum recently released a draft report suggesting that adjustment for socioeconomic factors may be appropriate when comparing quality of care across providers (http://www.quality
forum.org/National_Discussion_on_Risk_Adjustment. aspx). Further, CMS may need to examine community programs and target facilities located in socioeconomically deprived areas with interventions to increase kidney transplant access through reduction of neighborhood barriers. Such efforts may result in an overall reduction in socioeconomic disparities in access to kidney transplantation in the United States.

\section{Acknowledgements}

The authors of this manuscript are members of the Southeastern Kidney Transplant Coalition, a coalition with the mission to increase the kidney transplant rate in Georgia, North Carolina, and South Carolina by identifying barriers in the kidney transplant process. We acknowledge all members of the Southeastern Kidney Transplant Coalition, who helped motivate the initial analyses for this manuscript. We also thank Oluwaseun Odewole, MPH, for her assistance with geocoding and the University of Michigan Kidney Epidemiology and Cost Center for their assistance with data acquisition. Portions of this work were presented at the Society for Epidemiologic Research (SER) meeting, June 18-21, 2013, in Boston, MA, and at the SouthEast SAS Users Group (SESUG) conference, October 20-23, 2013, in St. Pete Beach, FL. R.E.P. was supported in part by grants from the National Center for Advancing Translational Sciences of the National Institutes of Health under Award Number ULl TR000454 and KL2TR000455. R.E.P. and S.O.P are both supported in part by 1R24MD008077-01 through the National Institute on Minority Health and Health Disparities. The content is solely the responsibility of the authors and does not necessarily represent the official views of the National Institutes of Health.

\section{Disclosure Statement}

The authors have no conflicts of interest to disclose.

\section{References}

1 Subramanian SV, Chen JT, Rehkopf DH, Waterman PD, Krieger N: Comparing individual- and area-based socioeconomic measures for the surveillance of health disparities: a multilevel analysis of Massachusetts births, 1989-1991. Am J Epidemiol 2006;164:823834.

-2 Cubbin C, Winkleby MA: Protective and harmful effects of neighborhood-level deprivation on individual-level health knowledge, behavior changes, and risk of coronary heart disease. Am J Epidemiol 2005;162:559-568.

-3 Nordstrom CK, Diez Roux AV, Jackson SA, Gardin JM: The association of personal and neighborhood socioeconomic indicators with subclinical cardiovascular disease in an elder- ly cohort. The cardiovascular health study. Soc Sci Med 2004;59:2139-2147.

4 Rossen LM: Neighbourhood economic deprivation explains racial/ethnic disparities in overweight and obesity among children and adolescents in the USA. J Epidemiol Commun Health 2014;68:123-129.

$\checkmark 5$ Kershaw KN, Diez Roux AV, Burgard SA, Lisabeth LD, Mujahid MS, Schulz AJ: Metropolitan-level racial residential segregation and black-white disparities in hypertension. Am J Epidemiol 2011;174:537-545.

6 Volkova N, McClellan W, Klein M, Flanders D, Kleinbaum D, Soucie JM, et al: Neighborhood poverty and racial differences in ESRD incidence. J Am Soc Nephrol 2008;19:356-364.
7 Krieger N, Chen JT, Waterman PD, Rehkopf DH, Subramanian SV: Painting a truer picture of US socioeconomic and racial/ethnic health inequalities: the Public Health Disparities Geocoding Project. Am J Public Health 2005;95:312-323.

-8 Port FK, Wolfe RA, Mauger EA, Berling DP, Jiang K: Comparison of survival probabilities for dialysis patients vs cadaveric renal transplant recipients. J Am Med Assoc 1993;270: 1339-1343.

$\checkmark 9$ Ojo AO, Port FK, Wolfe RA, Mauger EA, Williams L, Berling DP: Comparative mortality risks of chronic dialysis and cadaveric transplantation in black end-stage renal disease patients. Am J Kidney Dis 1994;24:59-64. 
10 Wolfe RA, Ashby VB, Milford EL, Ojo AO, Ettenger RE, Agodoa LY, et al: Comparison of mortality in all patients on dialysis, patients on dialysis awaiting transplantation, and recipients of a first cadaveric transplant. New Engl J Med 1999;341:1725-1730.

11 Evans RW, Manninen DL, Garrison LP Jr, Hart LG, Blagg CR, Gutman RA, et al: The quality of life of patients with end-stage renal disease. New Engl J Med 1985;312:553-559.

12 Kutner NG, Brogan D, Kutner MH: Endstage renal disease treatment modality and patients' quality of life. Longitudinal assessment. Am J Nephrol 1986;6:396-402.

13 Patzer RE, Amaral S, Klein M, Kutner N, Perryman JP, Gazmararian JA, et al: Racial disparities in pediatric access to kidney transplantation: does socioeconomic status play a role? Am J Transplant 2012;12:369-378.

$\checkmark 14$ Patzer RE, Sayed BA, Kutner N, McClellan WM, Amaral S: Racial and ethnic differences in pediatric access to preemptive kidney transplantation in the United States. Am J Transplant 2013;13:1769-1781.

15 Patzer RE, Amaral S, Wasse H, Volkova N, Kleinbaum D, McClellan WM: Neighborhood poverty and racial disparities in kidney transplant waitlisting. J Am Soc Nephrol 2009;20:1333-1340.

16 Patzer RE, Perryman JP, Schrager JD, Pastan S, Amaral S, Gazmararian JA, et al: The role of race and poverty on steps to kidney transplantation in the southeastern United States. Am J Transplant 2012;12:358-368.
17 Saunders MR, Cagney KA, Ross LF, Alexander GC: Neighborhood poverty, racial composition and renal transplant waitlist. Am J Transplant 2010;10:1912-1917.

18 Garg PP, Frick KD, Diener-West M, Powe NR: Effect of the ownership of dialysis facilities on patients' survival and referral for transplantation. New Engl J Med 1999;341: 1653-1660.

19 Patzer RE, Plantinga L, Krishner J, Pastan SO: Dialysis facility and network factors associated with low kidney transplantation rates among United States dialysis facilities. Am J Transplant 2014;14:1562-1572.

20 Wish JB, Meyer KB: ESRD Networks: past, present, and challenges for the future. Clin J Am Soc Nephrol 2012;7:1907-1914.

21 Patzer RE, Pastan SO: Kidney transplant access in the Southeast: view from the bottom. Am J Transplant 2014;14:1499-1505.

22 Guide to the 2011 region profiles for dialysis patients and facilities: overview, methodology, and interpretation. Ann Arbor, University of Michigan Kidney Epidemiology and Cost Center. Available at: http://www.dialysisreports.org/pdf/esrd/public/RegionGuide.pdf.

23 Messer LC, Kaufman JS: Using census data to approximate neighborhood effects; in Oakes JM, Kaufman JS (eds): Methods in Social Epidemiology, ed 1, San Francisco, John Wiley \& Sons, 2006, pp 209-236.
24 Sampson RJ, Morenoff JD, Gannon-Rowley T: Assessing 'neighborhood effects': social processes and new directions in research. Annu Rev Sociol 2002;28:443-478.

25 Sen A, Foster JE: On economic inequality. Oxford, Clarendon Press, 1997.

26 Vonesh EF: Generalized Linear and Nonlinear Models for Correlated Data: Theory and Applications Using SAS. Cary, SAS Institute, Inc., 2012.

27 Hall YN, O’Hare AM, Young BA, Boyko EJ, Chertow GM: Neighborhood poverty and kidney transplantation among US Asians and Pacific Islanders with end-stage renal disease. Am J Transplant 2008;8:2402-2409.

28 Diez Roux AV: The study of group-level factors in epidemiology: rethinking variables, study designs, and analytical approaches. Epidemiol Rev 2004;26:104-111.

29 Maripuri S, Ikizler TA, Cavanaugh KL: Prevalence of pre-end-stage renal disease care and associated outcomes among urban, micropolitan, and rural dialysis patients. Am J Nephrol 2013;37:274-280.

30 Plantinga LC, Kim M, Goetz M, Kleinbaum DG, McClellan W, Patzer RE: Pre-end-stage renal disease care not associated with dialysis facility neighborhood poverty in the United States. Am J Nephrol 2014;39:50-58.

31 Smith MD, Robson AM, Woodward RS, Michelman JE, Valerius TJ, Hong BA: Geographic access to health care services: the case of maintenance hemodialysis. Am J Kidney Dis 1985;5:19-26. 